\title{
Using gyro stabilizer for active anti- rollover control of articulated wheeled loader vehicles
}

\author{
Xiaoyu Zhang', Qianjie Liu', Jun Liu', Qingyuan Zhu' \\ and Huosheng $\mathrm{Hu}^{2}$
}

\begin{abstract}
Articulated wheeled loader vehicles have frequent rollover accidents as they operate in the complex outdoor environments. This article proposes an active anti-rollover control method based on a set of single-frame control moment gyro stabilizer installed on the rear body of the vehicle. The rollover dynamic model is first established for articulated wheeled loader vehicle with gyro stabilizer. The proposed control strategy is then applied in simulation to verify the rollover control effect on the vehicle under steady-state circumferential conditions. Finally, a home-built articulated wheel loader vehicle with gyro stabilizer is used to further verify the proposed control strategy. The results show that the vehicle can quickly return to the stable driving state and effectively avoid the vehicle rollover when a suitable anti-roll control moment can be provided by the gyro stabilizer. As a result, the articulated wheeled loader vehicle is able to operate safely in a complex outdoor environment.
\end{abstract}

\section{Keywords}

Articulated wheeled loader vehicle, anti-rollover control, single-frame control moment gyro, roll moment control, robust control

\section{Introduction}

Articulated wheeled loader vehicles have been widely used in construction, mining, agriculture and forestry due to their small turning radius, high operating efficiency and good maneuverability. However, they are prone to rollover accidents due to their variable center of mass, variable load and complicated working environments. ${ }^{1}$ Therefore, it is necessary to improve their anti-rollover ability to reduce the incidence of rollover accidents. ${ }^{2}$

In the 1970s, the anti-lock braking system (ABS) was developed to increase the stability of the vehicle during braking, which can shorten the braking distance for improved safety. ${ }^{3}$ Later, electronic braking system (EBS) was created to effectively reduce the reaction time of the air brake system and significantly shorten the braking distance. ${ }^{4}$ The roll stability control (RSC) system was invented to reduce the engine torque or differential braking to prevent the vehicle from rolling over. In addition, some vehicle auxiliary systems are used to improve vehicle stability by controlling the yaw moment of the vehicle. Wang et al. proposed a new active yaw stabilizer (AYS) system for improving vehicle lateral stability. They further designed the corresponding control strategy with the active rollover preventer (ARPer) system, which can reduce the number of rollover accidents. ${ }^{5,6}$ Goodarzi et al. ${ }^{7,8}$ introduced a stabilizer pendulum system for the direct yaw moment control to supervise the lateral dynamics of vehicle, which demonstrated its superior performance on low friction roads.

In addition, it is possible to improve the vehicle roll stability by introducing additional mechanisms. Sorniotti et al. ${ }^{9}$ used active anti-roll bars to suppress the rollover of the vehicle, which can effectively reduce the roll angle of the vehicle and provide a new antirollover control. To improve the roll stability of the

\footnotetext{
'Department of Mechanical and Electrical Engineering, Xiamen University, Xiamen, China

${ }^{2}$ School of Computer Science and Electronic Engineering, University of Essex, Colchester, UK
}

\section{Corresponding author:}

Qingyuan Zhu, Department of Mechanical and Electrical Engineering, Xiamen University, Xiamen 361005, China.

Email: zhuqy@xmu.edu.cn 


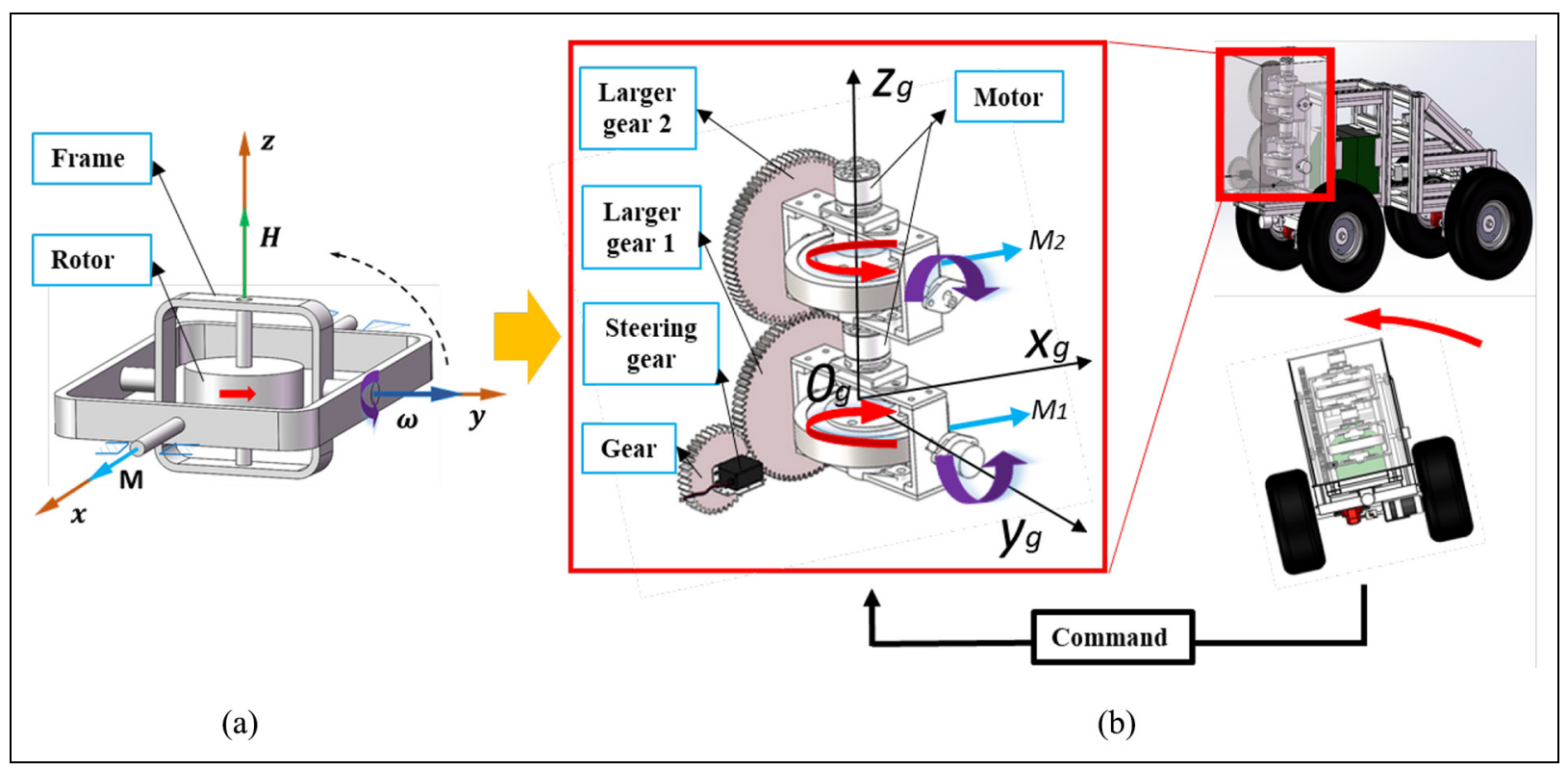

Figure I. Articulated wheeled loader vehicle with a gyro stabilizer: (a) single-frame control torque gyro and (b) the gyro stabilizer is fixed at the rear of the articulated wheel loader.

vehicle, a novel single-frame control torque gyro was introduced for attitude control of various systems. ${ }^{10,11}$ It can maintain the system balance and stably move forward and backward. ${ }^{12-14}$ Gyro stabilization technology was first applied to two-wheeled vehicles in which the power generated by the gyroscope acted on the vehicle to keep it upright during the movement. ${ }^{15}$ Mashadi et al. ${ }^{16,17}$ introduced a gyroscope device to prevent the vehicle from rolling over. The experimental results showed that the system can successfully stabilize the vehicle.

In this article, we design a gyro stabilizer for antirollover control of the articulated wheel loader vehicle. The dynamic model is established for the articulated wheel loader vehicle with the single-frame control moment gyro stabilizer. The rollover torque generated by the gyro stabilizer is controlled by linear matrix inequality (LMI) in real time to form the anti-rollover control strategy for the vehicle. The time to rollover $(\mathrm{TTR})^{18}$ is used as the trigger control condition, which indicated the rollover warning time. Moreover, the steady-state margin angle (SSMA) ${ }^{19}$ is used to monitor the effect of rollover control. The simulation analysis is first carried out under the steady-state circumferential conditions at different speeds. Then a home-built articulated wheeled loader vehicle is used to verify the effectiveness of the proposed rollover control scheme.

The rest of this article is organized as follows. Section "Rolling dynamic model of articulated wheeled loader vehicle with gyro stabilize" establishes the rollover dynamics model of the articulated wheeled loader vehicle with gyro stabilizer. Section "Anti-rollover robust control design" introduces the robust control design for anti-rollover. The numerical simulation analysis of the proposed rollover control scheme is carried out in section "Simulation analysis." A home-built articulated wheeled loader vehicle with a gyro stabilizer is used to conduct real experiments in section "Test verification." Finally, a brief conclusion is given in section "Conclusion" to summarize the work presented in the article.

\section{Rolling dynamic model of articulated wheeled loader vehicle with gyro stabilizer}

To actively suppress the vehicle rollover, we have added a gyro stabilizer on a home-built articulated wheeled loader vehicle. Figure 1 shows its structure, which is a scale-down version of real articulated wheeled loader vehicle. The gyro stabilizer is fixed at the rear of the vehicle body by four bolts, which is highlighted by a red box. The mechanism mainly consists of an oscillating steering gear and two single-frame control torque gyros. When the vehicle body is tilted and unstable, the control system sends a command to the steering gear.

As shown in Figure 1(a), a single-frame control torque gyro consists of a rotor, a frame and a frame rotation servo system. When the rotor and the frame rotate counterclockwise, the angular momentum $H$ of the rotor is along the positive direction of the $z$-axis, and the angular velocity $\omega$ of the frame is along the positive direction of the y-axis. $M$ is the output torque. According to the principle of gyro's precession effect, ${ }^{16,20}$ the output torque is equal to the vector product of the $\omega$ and $H$

$$
M=\omega \times H
$$

According to the rule of the right hand, the index finger points from $\omega$ to $H$, then the direction of the thumb is the direction of the output torque $M$, that is, the positive direction along the $x$-axis.

Similarly, as shown in Figure 1(b), when the vehicle body rolled toward the left, the steering gear drives the 
gear to rotate clockwise. Due to the larger gear 1 meshes with the gear, the lower frame is driven to swing counterclockwise. While the motor drives the lower rotor to rotate clockwise. Meanwhile, the larger gear 2 is meshed by the larger gear 1, and the upper frame is driven to swing clockwise, while the corresponding motor drives the upper rotor to rotate counterclockwise. Due to the opposite rotation of the rotor and wiggle of the frame respectively, the disturbance moments of the gyro stabilizer around the direction of $o_{g} y_{g}$ axis and $o_{g} z_{g}$ axis are offset and balanced. The output effective torques $M_{1}$ and $M_{2}$ around the $o_{g} x_{g}$ axis direction are superimposed based on the precession effect of the gyro device, thereby generating a roll moment to the right and adjusting the vehicle attitude to actively prevent the vehicle from rolling over. Conversely, when the vehicle body rolled toward the right, the gyro stabilizer will output an antirollover torque to the left.

According to the body structure characteristics of the articulated wheeled loader vehicle, we simplify it into the following three parts: (i) the front body (including the front axle and working device), (ii) the rear body and (iii) the rear axle. As shown in Figure 2, the ground reference coordinate system is defined as $O_{-} X Y Z$, the vehicle body coordinate system is $o_{-} x y z$, the front vehicle body reference coordinate system is $O_{f-} X_{f} Y_{f} Z_{f}$, the rear body reference coordinate system is $O_{r-} X_{r} Y_{r} Z_{r}$, and the rear axle reference coordinate system is $O_{b-} X_{b} Y_{b} Z_{b}$.

Assume that the longitudinal vehicle speed $u$ is constant. The four degrees-of-freedom dynamic model of articulated wheeled loader vehicle includes the lateral displacement $y$ of the vehicle, the yaw angle $r_{f}$ of the front body, the yaw angle $r_{r}$ of the rear body and the roll angle $\varphi$ of the vehicle. The differential motion equation for the vehicle system is established by the second type of Lagrange equation as follows

$$
\frac{d}{d t}\left(\frac{\partial E_{T}}{\partial \dot{q}_{i}}\right)-\frac{\partial E_{T}}{\partial q_{i}}+\frac{\partial E_{V}}{\partial q_{i}}+\frac{\partial E_{D}}{\partial \dot{q}_{i}}=Q_{i}
$$

where $E_{T}, E_{V}$ and $E_{D}$ represent the kinetic energy, the potential energy and the dissipative energy of the vehicle respectively; $q_{i}$ is the generalized coordinates, and the generalized coordinates $q_{1}=y, q_{2}=r_{f}, \quad q_{3}=r_{r}$, $q_{4}=\varphi ; Q_{i}$ means the generalized force.

The dynamic equation of single-frame control moment gyro is given below

$$
\left\{\begin{array}{c}
M_{x}=J_{x} \ddot{\varphi} \cos \beta+H \dot{\beta} \\
M_{y}=J_{y} \ddot{\beta}-H \dot{\alpha} \cos \beta \\
M_{z}=0
\end{array}\right.
$$

where $M_{x}, M_{y}$ and $M_{z}$ are components directly acting on the gyro rotor along the coordinate axis $x, y$ and $z$, respectively; $J_{x}$ and $J_{y}$ are the inertia moments of the gyro rotor on the $x$ and $y$ axes, respectively; $\beta$ is the gyro precession angle; $H$ is the gyro momentum moment; $\alpha$ is the rotation angle of the gyroscope around the horizontal axis of the outer frame axis.

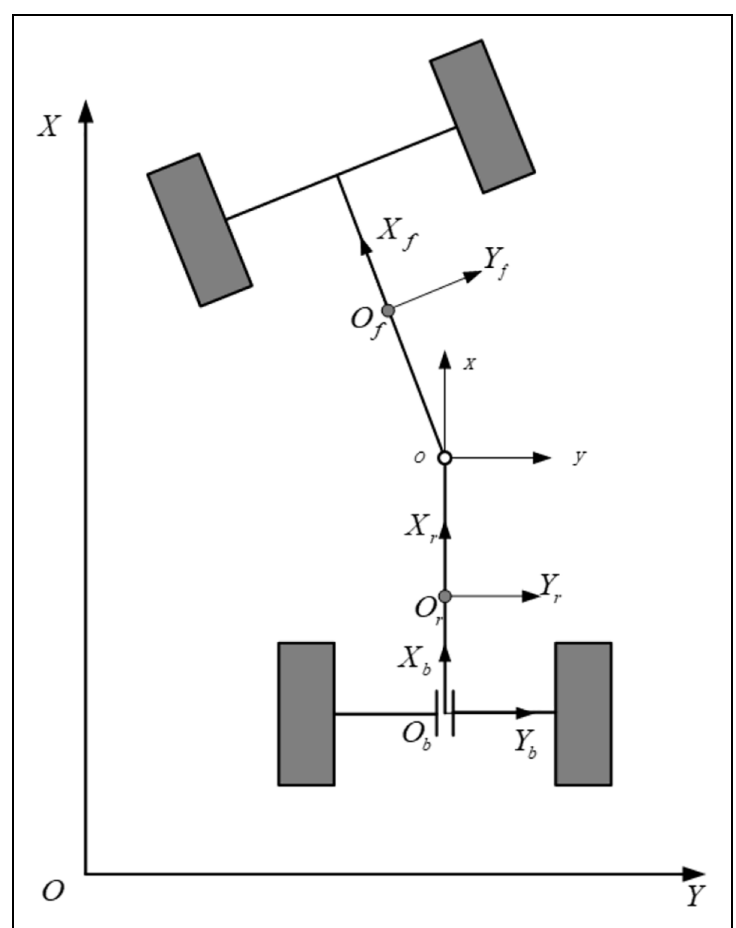

Figure 2. Modeling coordinate system of an articulated wheeled loader vehicle.

In the gyro stabilization device, the rotors of the two single-frame control moment gyros have equal magnitude and opposite direction, and the rotor rotation speeds are equal and opposite directions. The output disturbance moments around the $o_{g} y_{g}$ axis direction have offset each other, and the output effective moments around the $o_{g} x_{g}$ axis direction have overlapped each other. Therefore, the dynamic equation of the gyro stabilizer is

$$
\left\{\begin{array}{c}
M_{x}=J_{x} \ddot{\varphi} \cos \beta_{1}+H_{1} \dot{\beta}_{1}+J_{x} \ddot{\varphi} \cos \beta_{2}+H_{2} \dot{\beta}_{2} \\
M_{y}=0 \\
M_{z}=0
\end{array}\right.
$$

By projecting equation (4) into the vehicle body coordinate system $o_{-} x y z$, we can obtain

$$
\left\{\begin{array}{c}
M_{x}=J_{x} \ddot{\varphi} \cos ^{2} \beta_{1}+H_{1} \dot{\beta}_{1} \cos \beta_{1}+J_{x} \ddot{\varphi} \cos ^{2} \beta_{2} \\
+H_{2} \dot{\beta}_{2} \cos \beta_{2} \\
M_{y}=0 \\
M_{z}=0
\end{array}\right.
$$

As $\beta$ value is small, $\beta_{1}=\beta_{2}=\beta, H_{1}=H_{2}=H$, formula (5) can be simplified to

$$
\left\{\begin{array}{c}
M_{x}=2 \times\left(J_{x} \ddot{\varphi}+H \beta\right) \\
M_{y}=0 \\
M_{z}=0
\end{array}\right.
$$

By combining equations (2) and (6), the differential equation of the vehicle system motion can be obtained below 


$$
\left\{\begin{array}{l}
\frac{d}{d t}\left(\frac{\partial E_{T}}{\partial \dot{y}}\right)-\frac{\partial E_{T}}{\partial y}+\frac{\partial E_{V}}{\partial y}+\frac{\partial E_{D}}{\partial \dot{y}}=Q_{y} \\
\frac{d}{d t}\left(\frac{\partial E_{T}}{\partial \dot{r}_{f}}\right)-\frac{\partial E_{T}}{\partial r_{f}}+\frac{\partial E_{V}}{\partial r_{f}}+\frac{\partial E_{D}}{\partial \dot{r}_{f}}=Q_{r_{f}} \\
\frac{d}{d t}\left(\frac{\partial E_{T}}{\partial \dot{r}_{r}}\right)-\frac{\partial E_{T}}{\partial r_{r}}+\frac{\partial E_{V}}{\partial r_{r}}+\frac{\partial E_{D}}{\partial \dot{r}_{r}}=Q_{r_{r}} \\
\frac{d}{d t}\left(\frac{\partial E_{T}}{\partial \dot{\varphi}}\right)-\frac{\partial E_{T}}{\partial \varphi}+\frac{\partial E_{V}}{\partial \varphi}+\frac{\partial E_{D}}{\partial \dot{\varphi}}+M_{x}=Q_{\varphi}
\end{array}\right.
$$

The kinetic energy, potential energy and dissipation energy of the vehicle system are solved separately. The generalized force is solved by the virtual work principle. The motion differential equation of the system is

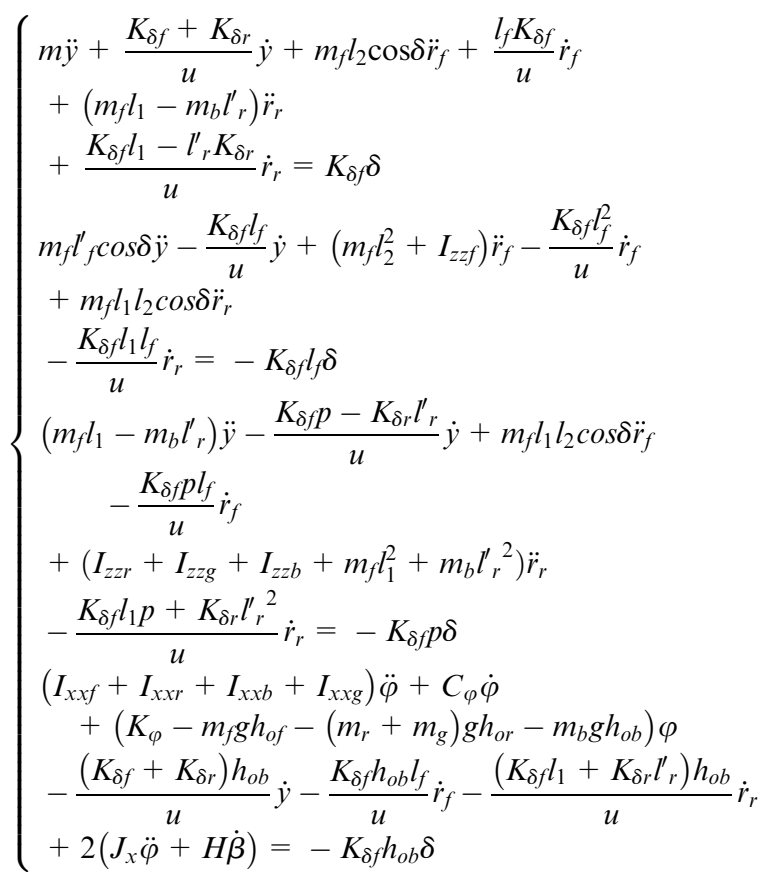

where $m_{f}, m_{r}$ and $m_{b}$ are the masses of the front body (including front axle and working device), rear body and rear axle, respectively; $I_{x x f}, I_{x x r}$ and $I_{x x b}$ are the roll moment of inertia of the front body, rear body and rear axle, respectively; $I_{z z f}, I_{z z r}$ and $I_{z z b}$ are the yaw moment of inertia of the front body, rear body and rear axle, respectively; $l_{1}$ and $l_{2}$ are the distance from the rear body center of gravity and the front body center of gravity to the hinged center; $l_{r}$ and $l_{r}^{\prime}$ are the distance from the hinged center and rear body center of gravity to the rear axle center; $l_{f}$ and $l_{f}^{\prime}$ are the distance from the hinged center and the front body center of gravity to the front axle center; $g$ is the gravitational acceleration; $h_{o f}$ is the height of the front body; $h_{o r}$ and $h_{o b}$ are the roll heights of the rear body and rear axle respectively; $K_{\delta A}, K_{\delta B}, K_{\delta C}$ and $K_{\delta D}$ are the cornering stiffness of each tire; $K_{\varphi}$ and $C_{\varphi}$ are the roll stiffness coefficient and the roll damping coefficient of the tire respectively; $m=m_{f}+m_{r}+m_{b}+m_{g} ; K_{\delta f}=K_{\delta A}+K_{\delta B} ; K_{\delta r}=K_{\delta C}$ $+K_{\delta D} ; p=\sqrt{l_{1}^{2}+l_{f}^{2}+2 l_{1} l_{f} \cos \beta}$

The control torque $f$ of the gyro stabilizer is selected as the control input, and the steering angle $\delta$ is selected as the external disturbance input. Equation (8) can be rewritten into the standard state equation below

$$
\dot{x}=Q x+R u+G \delta
$$

where $x=\left[y, r_{f}, r_{r}, \varphi, \delta, \dot{y}, \dot{r}_{f}, \dot{r}_{r}, \dot{\varphi}, \dot{\delta}\right]^{T} ; u=f$

$$
\begin{aligned}
& \boldsymbol{Q}=\left[\begin{array}{cc}
\boldsymbol{O} & \boldsymbol{I} \\
-\boldsymbol{M}^{-1} \boldsymbol{K} & -\boldsymbol{M}^{-1} \boldsymbol{C}
\end{array}\right] \\
& \boldsymbol{R}=\left[\begin{array}{c}
\boldsymbol{O} \\
\boldsymbol{M}^{-1}
\end{array}\right] \\
& \boldsymbol{G}=\left[\begin{array}{c}
\boldsymbol{O} \\
\boldsymbol{M}^{-1} \boldsymbol{F}
\end{array}\right]
\end{aligned}
$$

where

$$
M=\left[\begin{array}{ccccc}
m & m_{f} l_{2} \cos \delta & m_{f} l_{l}-m_{b} l_{r}^{\prime} & 0 & 0 \\
m_{f} l_{f}^{\prime} \cos \delta & m_{f} l_{2}^{2}+I_{z z f} & m_{f} l_{l} l_{2} \cos \delta & 0 & 0 \\
m_{f} l_{l}-m_{b} l_{r}^{\prime} & m_{f} l_{l} l_{2} \cos \delta & I_{z z r}+I_{z z g}+I_{z z b}+m_{f} l_{1}^{2}+m_{b} l_{r}^{\prime 2} & 0 & 0 \\
0 & 0 & 0 & I_{x x f}+I_{x x r}+I_{x x b}+3 I_{x x g} & 0 \\
0 & 0 & 0 & 0 & 1
\end{array}\right]
$$

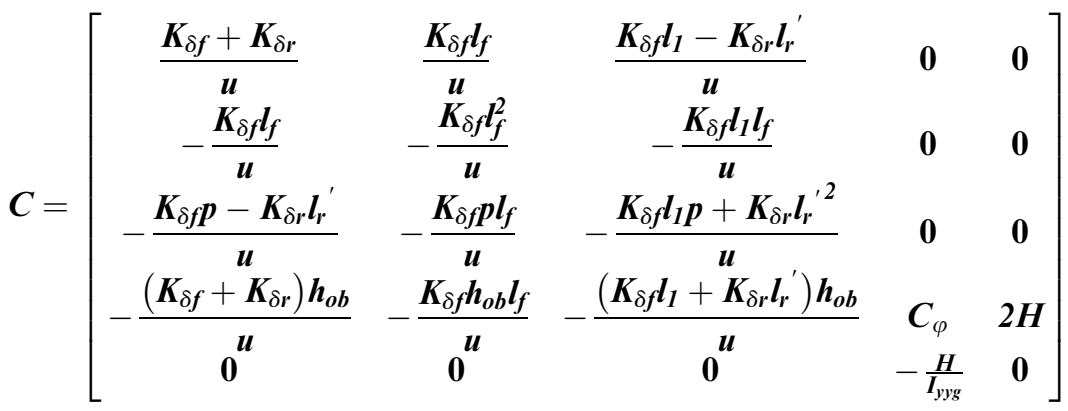

$$
\boldsymbol{K}=\left[\begin{array}{ccccc}
\mathbf{0} & \mathbf{0} & \mathbf{0} & \mathbf{0} & \mathbf{0} \\
\mathbf{0} & \mathbf{0} & \mathbf{0} & \mathbf{0} & \mathbf{0} \\
\mathbf{0} & \mathbf{0} & \mathbf{0} & \mathbf{0} & \mathbf{0} \\
\mathbf{0} & \mathbf{0} & \mathbf{0} & \boldsymbol{K}_{\varphi}-\boldsymbol{m}_{f} \boldsymbol{g} \boldsymbol{h}_{o f}-\boldsymbol{m}_{\boldsymbol{r}} \boldsymbol{g} \boldsymbol{h}_{\boldsymbol{r}}-\boldsymbol{m}_{g} \boldsymbol{g} \boldsymbol{h}_{o g} & \mathbf{0} \\
\mathbf{0} & \mathbf{0} & \mathbf{0} & \mathbf{0} & \mathbf{0}
\end{array}\right]
$$




$$
\boldsymbol{F}=\left[\begin{array}{c}
\boldsymbol{K}_{\delta f} \\
-\boldsymbol{K}_{\delta f} \boldsymbol{l}_{f} \\
-\boldsymbol{K}_{\delta f} \boldsymbol{p} \\
-\boldsymbol{K}_{\delta \boldsymbol{f}} \boldsymbol{h}_{o b} \\
\mathbf{0}
\end{array}\right]
$$

$Q, R$ and $G$ are the coefficient matrices corresponding to the state vector and the input vectors.

\section{Anti-rollover robust control design}

\section{Design of $L M I$ robust controller}

SSMA is an instability prediction index combined with the first-order instability and second-order instability states of an articulated wheel loader for evaluating the state of motion of a vehicle body. ${ }^{19}$ It can evaluate the lateral stability of the vehicle according to vehicle motion state without considering the external rollover factors. Therefore, the SSMA can be used to accurately monitor the rollover dynamics of the vehicle. SSMA is an included angle between the resultant force vector and the defined stable surface, in which the resultant force vector is the synthesis of inertial force and gravity. When the SSMA is less than 0 , the vehicle is unstable and at the risk of rollover. When the SSMA is larger than 0 , the vehicle is stable and has no risk of rollover. To use the gyro stabilizer for anti-rollover active control of the vehicle, this article designs a state feedback robust controller for realizing the real-time adjustment of the control torque of the gyro stabilizer. Figure 3 shows flowchart of an LMI state feedback control system.

The control system aims to stabilize the closed-loop system internally and to satisfy $\left\|T_{w z}(s)\right\|_{\infty}<1$, in which $T_{w z}(s)$ is the closed-loop transfer function from the disturbance input $\delta$ to the adjusted function $z$. If the state feedback gain of the system is $K$, the gyro stabilizer then controls the torque $u=K x$, and the corresponding closed-loop system can be expressed as

$$
\left\{\begin{array}{c}
\dot{x}=\left(Q+B_{u} K\right) x+G \delta \\
z=\left(C_{0}+D_{12} K\right) x+D_{11} \delta
\end{array}\right.
$$

where $B_{u}=R ; C_{0}, D_{11}$ and $D_{12}$ are the coefficient matrices that determine the controlled output $z$.

For a given scalar $\gamma>0$ under the LMI framework, we have only one symmetric positive definite matrix $X$ such that the following optimization constraint inequalities are obtained

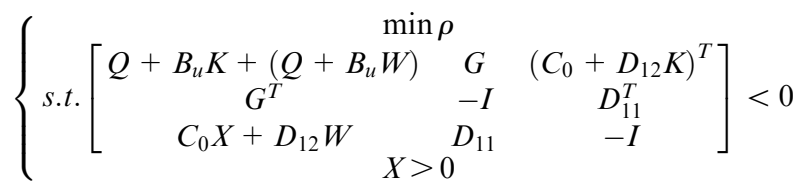

For this linear objective function optimization problem, the mincx function solver is selected. Finally, the optimal solutions $\gamma, X$ and $W$ are obtained. The

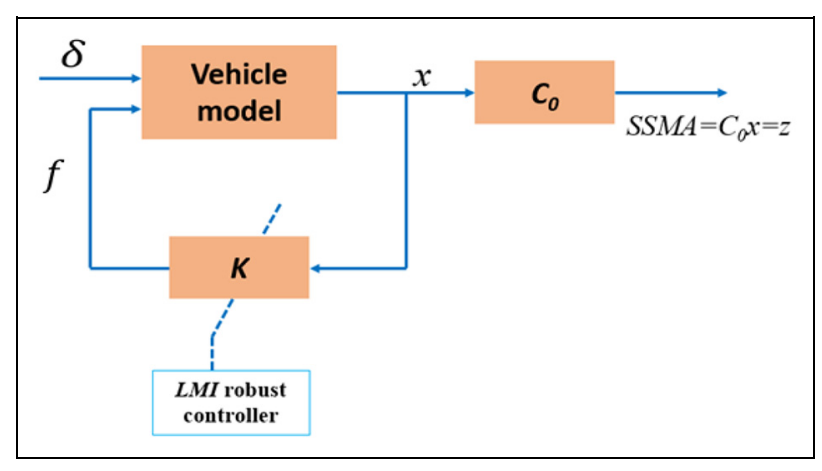

Figure 3. LMI state feedback control system.

controller state feedback gain can be obtained by $K=W(X)^{-1}$. The system is closed-loop stable.

\section{Anti-rollover robust control based on TTR rollover warning}

The rollover warning algorithm can predict whether the vehicle will reach the vehicle roll angle threshold under the current vehicle state and steering wheel input, which can be used to calculate the warning time TTR and generate the trigger signal. TTR represents the time interval from normal motion to vehicle rollover. When this time value is close to 0 , it indicates that the rollover risk of the vehicle is high. The optimal gyro stabilizer control torque is obtained using the designed LMI robust controller and the SSMA is used to evaluate the control effect. Figure 4 shows the schematic diagram of antirollover robust control based on TTR rollover warning.

The direct roll torque control method is adopted in this article to adjust the precession torque of the gyro stabilizer for controlling the roll stability of the articulated wheeled loader vehicle. The articulated steering angle is first input into the early warning reference model for state parameter estimation of the vehicle system, and the rollover warning algorithm is then used to iteratively calculate the warning time TTR. The implementation of the direct roll moment control is based on the factor of whether the rollover warning time TTR satisfies the roll condition (TTR $<T_{u p}$, where $T_{u p}$ is the warning threshold for TTR).

The LMI robust controller is combined with the positive and negative roll angle $\varphi$ to determine whether the vehicle turns left or right. If $\varphi>0$, the LMI robust controller outputs the rightward roll moment. On the contrary, the roll torque to the left is output. Therefore, the roll torque is accurately controlled according to the state feedback gain of the vehicle, and the posture of the vehicle body is corrected in time to avoid the occurrence of rollover accident.

\section{Simulation analysis}

To obtain the critical speed of vehicle rollover instability and verify the effectiveness of the gyro stabilizer 


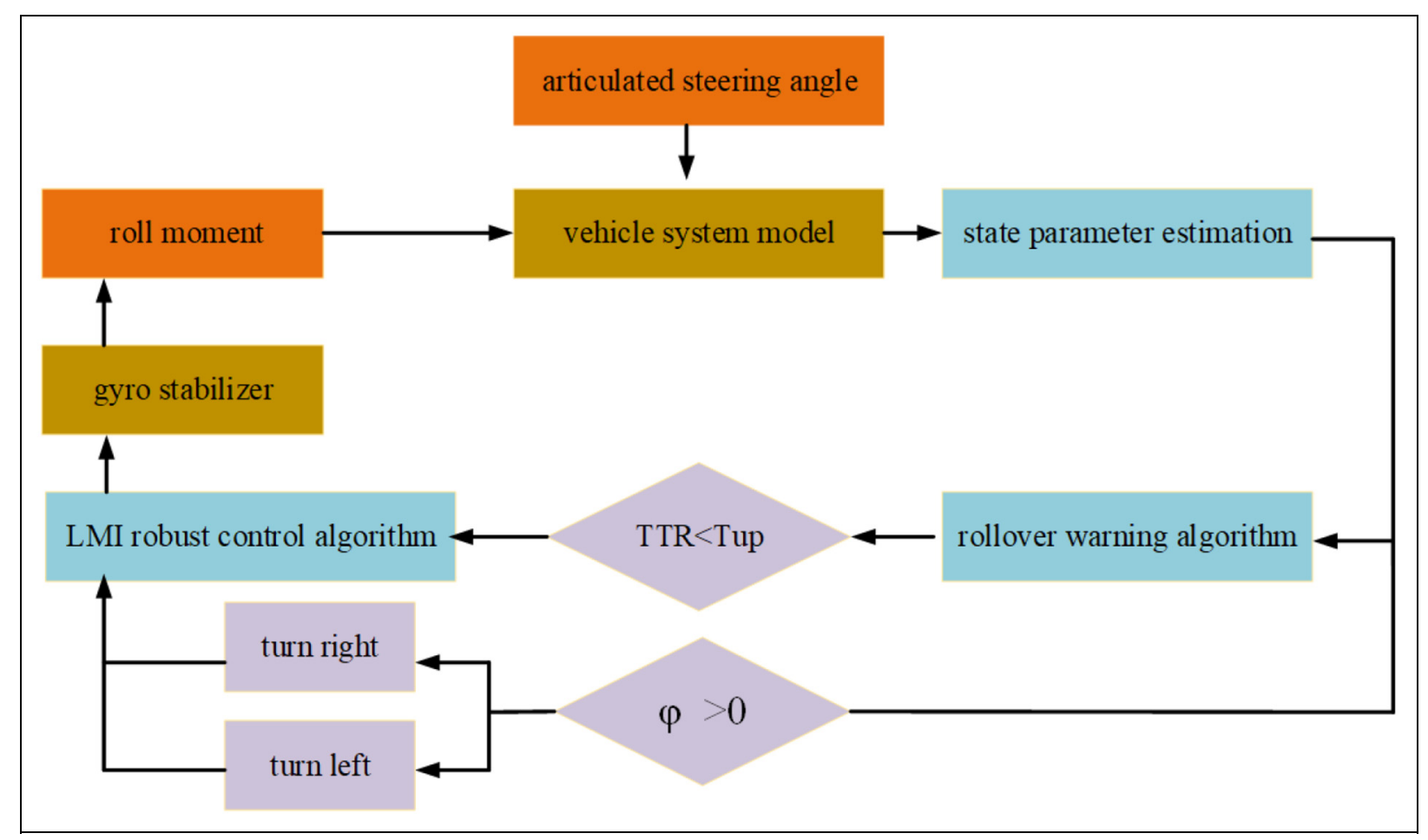

Figure 4. Schematic diagram of anti-rollover robust control based on TTR rollover warning.

Table I. Dimensions and specifications. ${ }^{21,22}$

\begin{tabular}{lll}
\hline Parameters & Explanation & Value \\
\hline$m(\mathrm{~kg})$ & Total mass of the prototype & 56.1 \\
$m_{f}(\mathrm{~kg})$ & Front body mass & 16.4 \\
$m_{r}(\mathrm{~kg})$ & Rear body mass & 26.4 \\
$m_{b}(\mathrm{~kg})$ & Rear axle mass & 13.3 \\
$I_{x x f}, I_{y y f}, I_{z z f}\left(\mathrm{~kg} \mathrm{~m}^{2}\right)$ & Moment of inertia of front body & $0.642,1.57,1.68$ \\
$I_{x x r}, I_{y y r}, I_{z z r}\left(\mathrm{~kg} \mathrm{~m}^{2}\right)$ & Moment of inertia of rear body & $0.765, I .79, I .25$ \\
$I_{x x b}, l_{y y b}, I_{z z b}\left(\mathrm{~kg} \mathrm{~m}^{2}\right)$ & Moment of inertia of rear axle & $0.413,1.58,1.89$ \\
$W_{F}\left(X_{1} / Y_{1} / Z_{1}\right)(\mathrm{m})$ & Center of gravity of front body & $0.26,0,0.005$ \\
$W_{F}\left(X_{2} / Y_{2} / Z_{2}\right)(\mathrm{m})$ & Center of gravity of rear body & $-0.19,0,0.14$ \\
$W_{F}\left(X_{3} / Y_{3} / Z_{3}\right)(\mathrm{m})$ & Center of gravity of rear axle & $-0.33,0,-0.04$ \\
$B(\mathrm{~m})$ & Wheel track & 0.45 \\
$I_{f}(\mathrm{~m})$ & Distance between pivot joint and the center of the front axle & 0.32 \\
$I_{r}(\mathrm{~m})$ & Distance between pivot joint and the center of the rear axle & 0.32 \\
$R_{t}(\mathrm{~m})$ & Tire radius & 0.15 \\
$h(\mathrm{~m})$ & Distance between rear axle shaft and rear body longitude axis & 0.02 \\
$K_{\alpha}\left(\mathrm{N} /{ }^{\circ}\right)$ & Cornering stiffness of tire & 81,600 \\
$K_{V}(\mathrm{~N} / \mathrm{m})$ & Vertical stiffness of tire & 20,000 \\
$C_{V}(\mathrm{Ns} / \mathrm{m})$ & Vertical damping of tire & 5000 \\
\hline
\end{tabular}

based anti-rollover control scheme, the numerical simulation and analysis are conducted under steady-state circumferential conditions. The TTR threshold of the rollover warning time is set to $3 \mathrm{~s}$, and SSMA is used to monitor the effect of rollover control. Table 1 shows the relevant parameters of the vehicle roll dynamics model. The maximum speed of the gyro stabilizer is $13,000 \mathrm{r} / \mathrm{min}$, and its moment of inertia is $0.0064 \mathrm{~kg} \mathrm{~m}^{2}$.

Figure 5 shows the step input of the steering angle of the vehicle front wheel under a uniform circular motion. The vehicle starts to turn at $3 \mathrm{~s}$ and reaches to $20^{\circ}$ within $2 \mathrm{~s}$. The steering angle of the articulated wheeled loader vehicle is within $0^{\circ}-40^{\circ}$. Therefore, the steering angle is selected to be $20^{\circ}$ in the steady-state circumferential condition, and the vehicle speed is set to $1.25-3 \mathrm{~m} / \mathrm{s}$.

Figure 6 shows the variation curve of SSMA and TTR when the vehicle is traveling at a constant speed of $1.25 \mathrm{~m} / \mathrm{s}$. It can be seen that SSMA gradually decreases toward around 18 in the steering process of the vehicle and TTR remains constant. As the vehicle is in a safe driving state and has no risk of rollover, active 


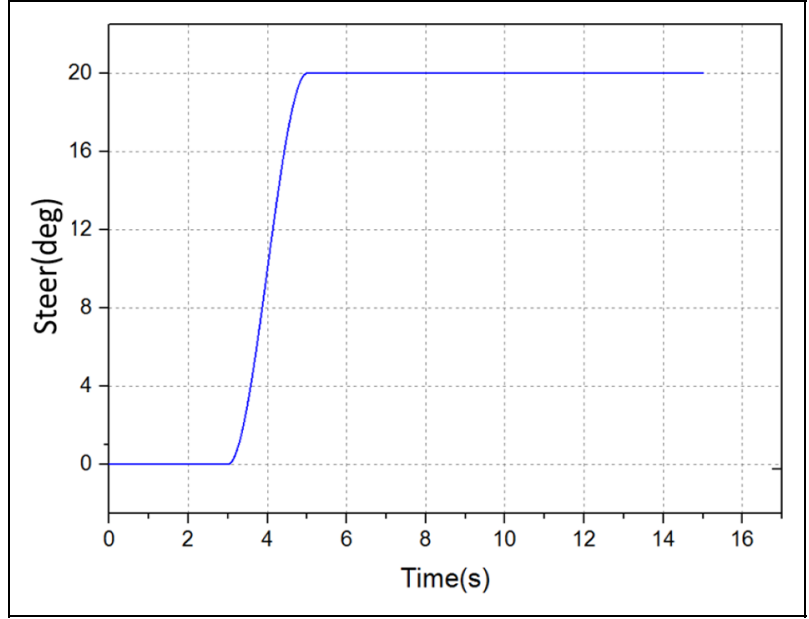

Figure 5. Articulated steering angle input. anti-rollover safety control is not required. When the vehicle increases its speed under the steady-state circumferential condition, its SSMA performance gradually decreases. When the vehicle speed reaches $3 \mathrm{~m} / \mathrm{s}$, SSMA reaches the critical threshold. Figure 7 shows the corresponding variation curve of SSMA and TTR. As can be seen, SSMA reaches 0 at $5 \mathrm{~s}$ when the vehicle turns, and TTR decreases from 3 to 0 . By continuously increasing the vehicle speed at different steering angles, a large number of circular motion simulation experiments are carried out.

The roll stability of the vehicle with SSMA at different speeds and steering angles is present in Figure 8. It can be seen that SSMA is decreasing rapidly with the vehicle speed under an increasing steering angle. The vehicle is critically unstable under the condition of a vehicle speed of $3 \mathrm{~m} / \mathrm{s}$ and a steering angle of $20^{\circ}$. This

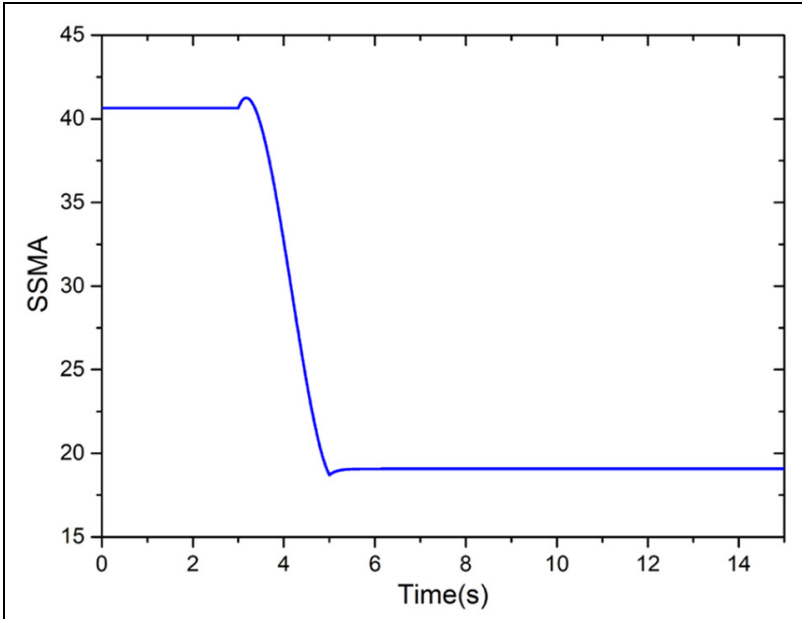

(a)

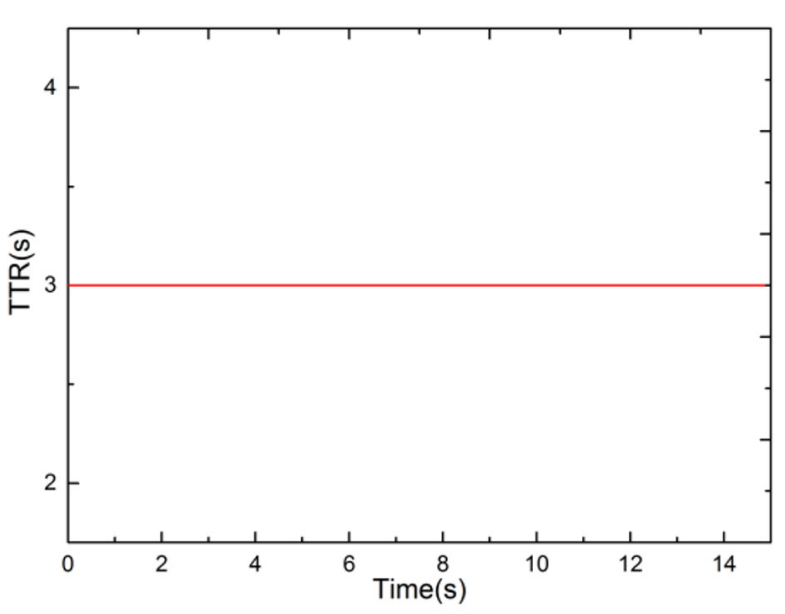

(b)

Figure 6. SSMA and TTR with a speed of $1.25 \mathrm{~m} / \mathrm{s}$ : (a) SSMA and (b) TTR.

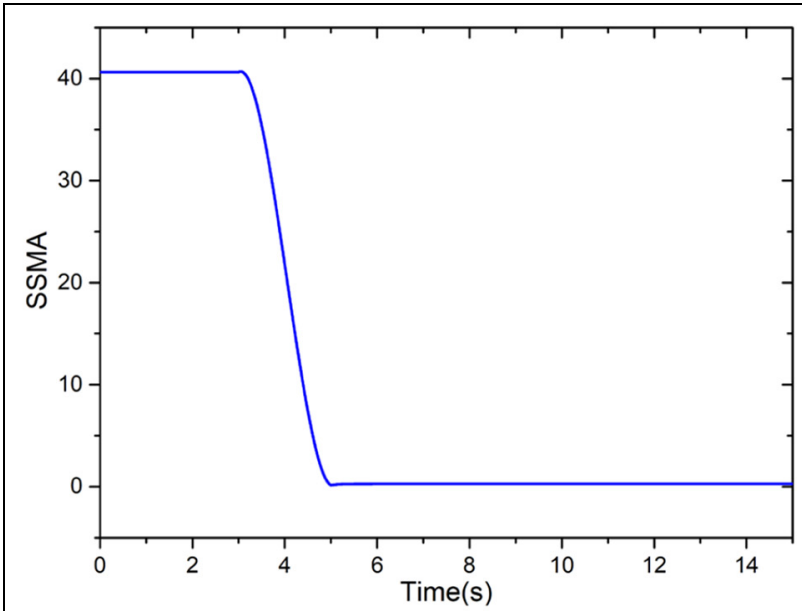

(a)

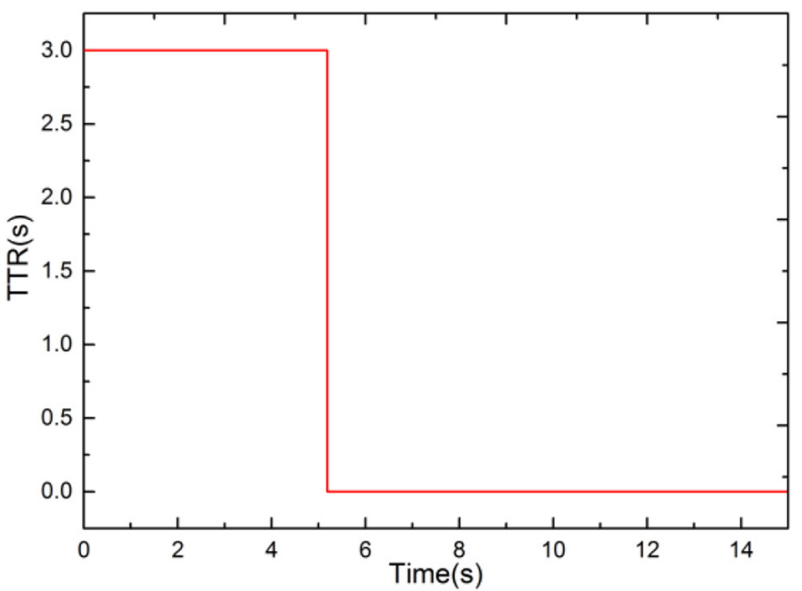

(b)

Figure 7. SSMA and TTR with a speed of $3 \mathrm{~m} / \mathrm{s}$ : (a) SSMA and (b) TTR. 


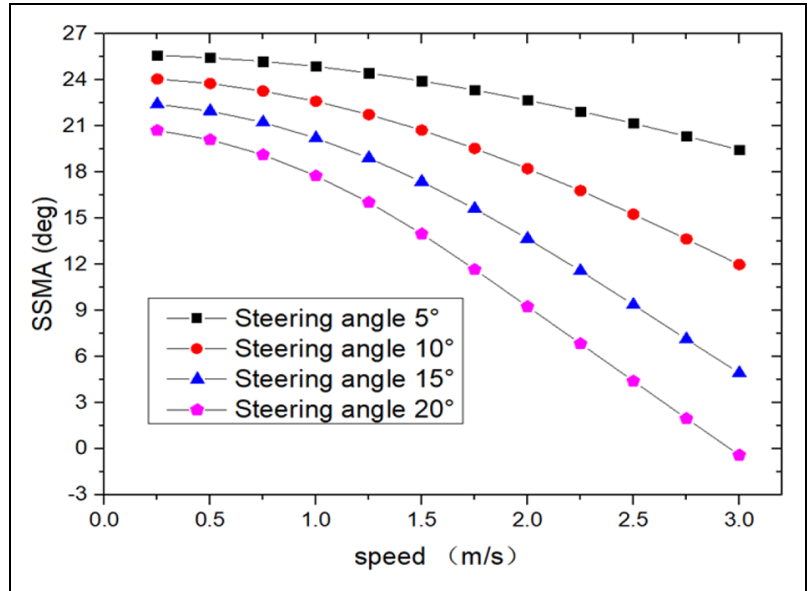

Figure 8. SSMA at different speeds and steering angles.

is consistent with the analysis of rollover instability at different speeds. Therefore, the speed $3 \mathrm{~m} / \mathrm{s}$ is the critical speed of the vehicle's rollover instability under steady-state circumferential conditions. It becomes necessary to apply active anti-rollover safety control to prevent the rollover accident when the speed is over $3 \mathrm{~m} / \mathrm{s}$.

To verify the effectiveness of the proposed rollover control scheme, we conducted the numerical simulation analysis by choosing the vehicle speed at 3 and $5 \mathrm{~m} / \mathrm{s}$ under steady-state circumferential conditions. Figures 9 and 10 show the effect of the vehicle's anti-rollover control at 3 and $5 \mathrm{~m} / \mathrm{s}$ respectively. As can be seen from Figure 9(a) and (b), the roll angle and roll rate are getting larger during the steering process. When active roll moment control is applied, they are reduced and returned dramatically. Since the roll angle changes rapidly, the roll rate reaches a peak in near $7.5 \mathrm{~s}$ and quickly returns to the positive. When the roll moment control is not implemented, the steering angle of the vehicle reaches the maximum and the roll angle rate increase to the maximum value and then decreased.

As shown in Figure 9(c) and (d), TTR and SSMA drop to 0 as the time reached $5 \mathrm{~s}$ and the critical instability occurred. After the roll torque control is applied, TTR is quickly returned to the normal value

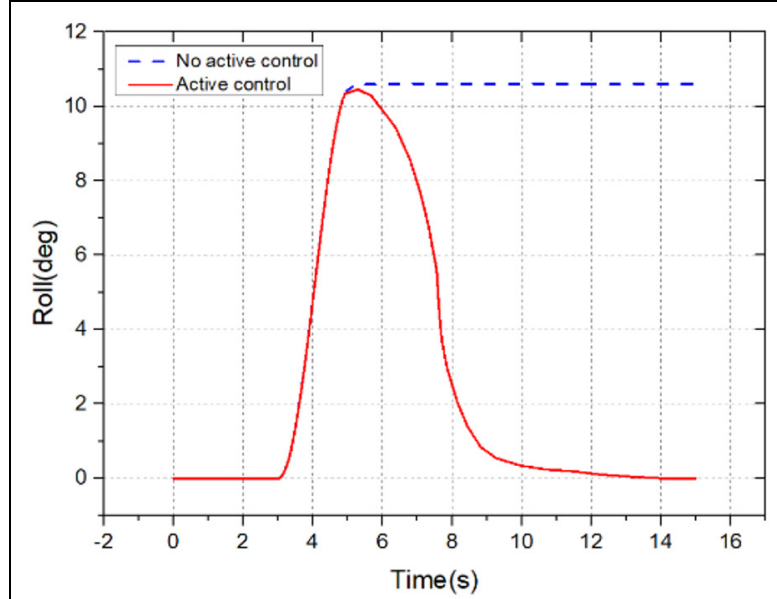

(a)

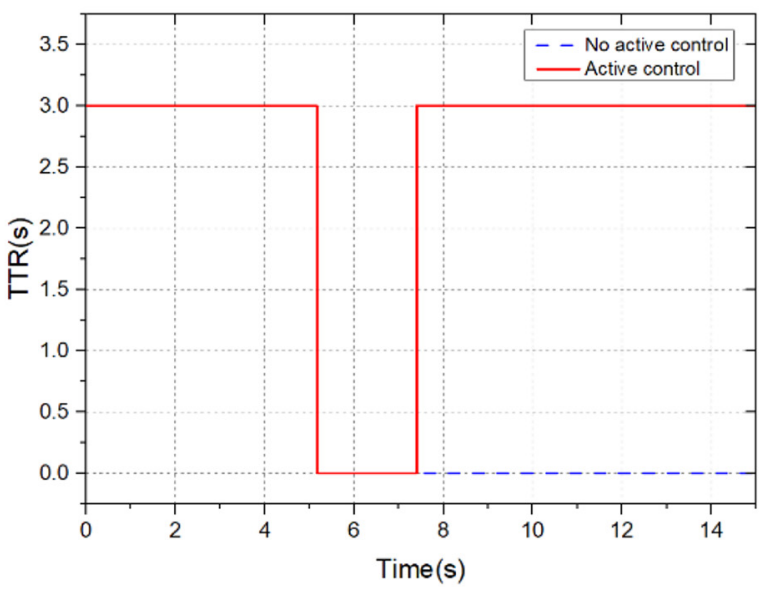

(c)

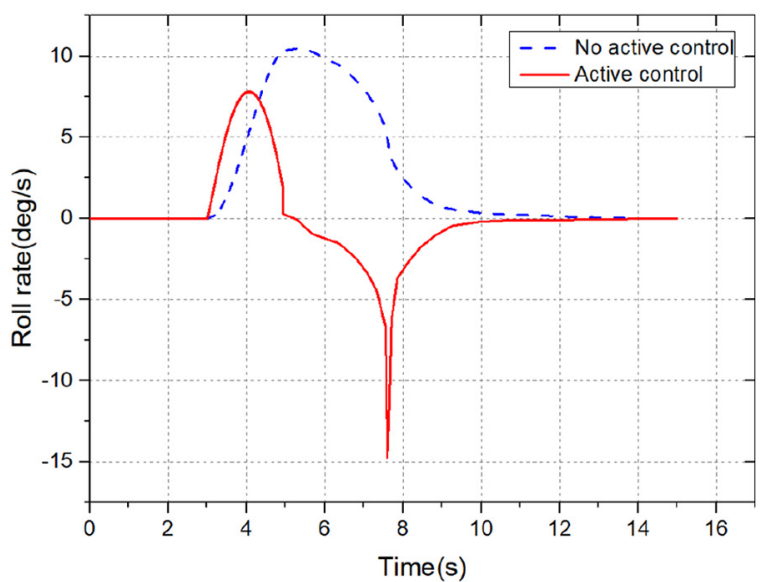

(b)

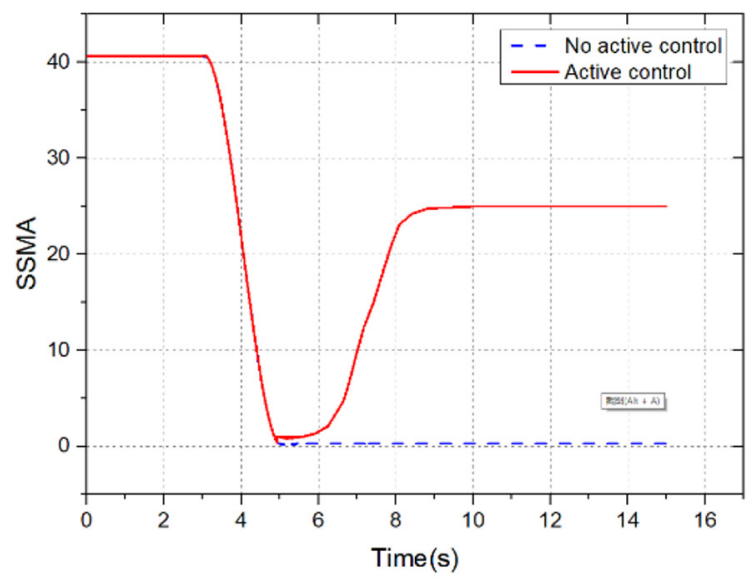

(d)

Figure 9. Comparison of vehicle anti-rollover control effects at $3 \mathrm{~m} / \mathrm{s}$ : (a) roll angle, (b) roll rate, (c) TTR and (d) SSMA. 


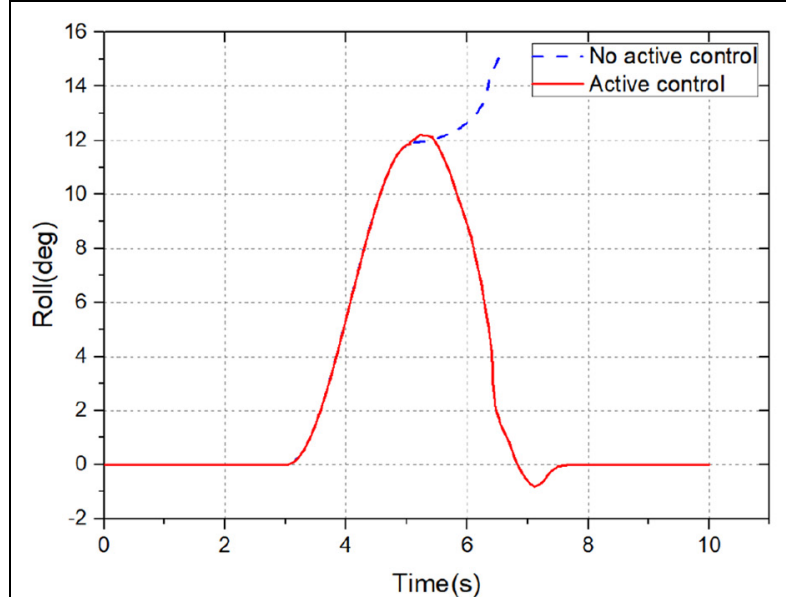

(a)

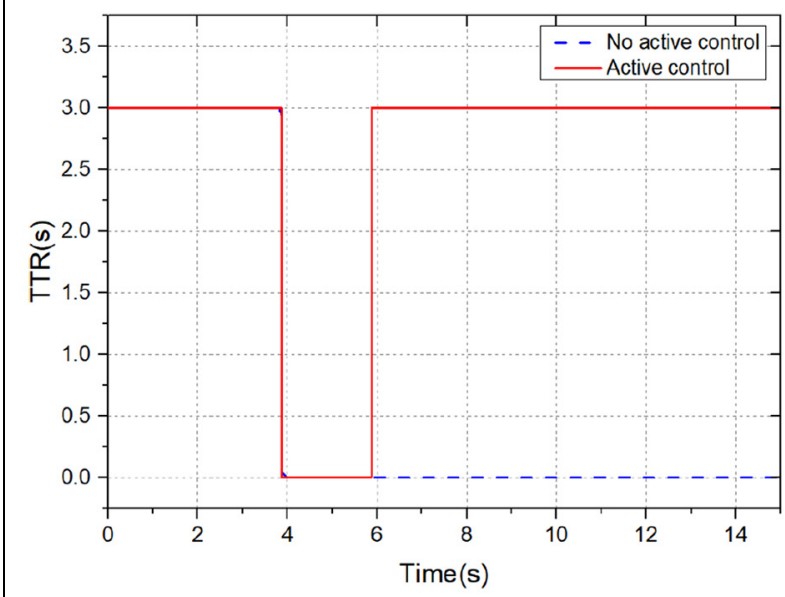

(c)

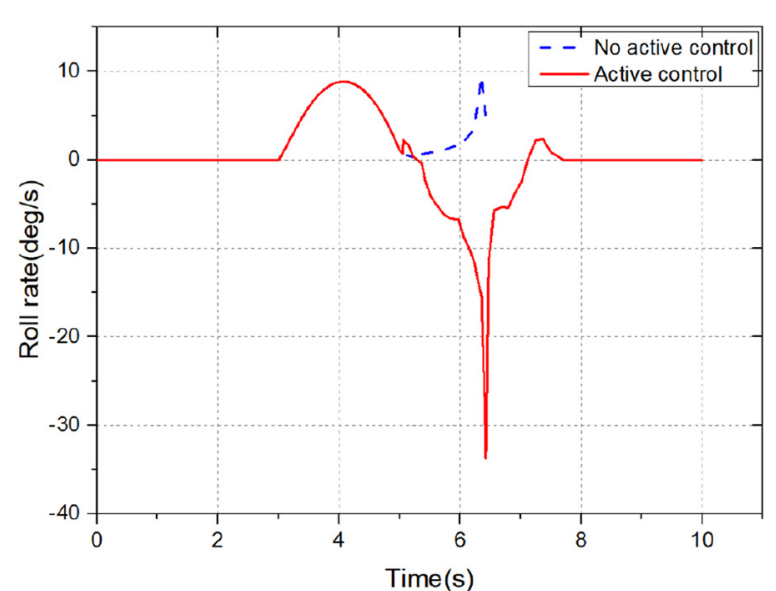

(b)

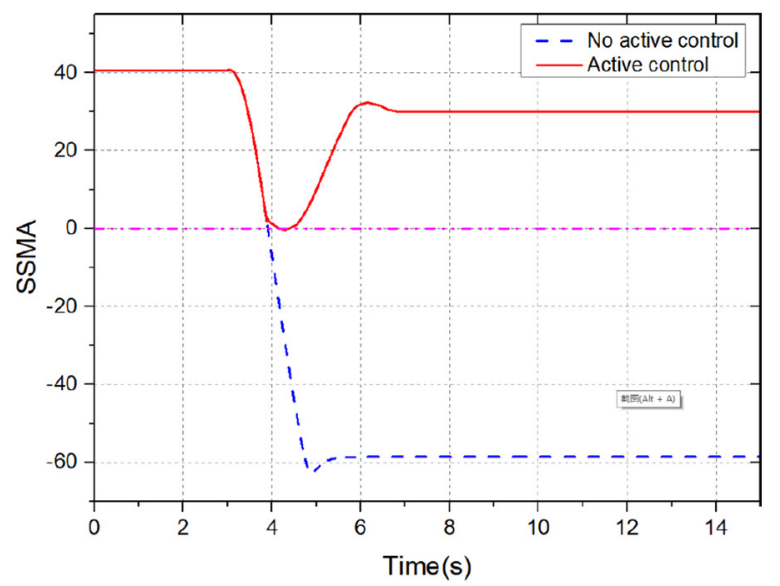

(d)

Figure 10. Comparison of anti-rollover control effects of vehicles at $5 \mathrm{~m} / \mathrm{s}$ : (a) roll angle, (b) roll rate, (c) TTR and (d) SSMA.

within $2.5 \mathrm{~s}$, that is, the vehicle changes from the critical instability state to the steady state. At the same time, SSMA is also returned to positive in a short time and remained unchanged until reaching $26^{\circ}$.

Figure 10(a) and (b) shows that the vehicle roll angle and roll rate continued to increase until the vehicle rollover (dashed line) due to the increased vehicle speed when the gyro stabilizer roll moment control is not applied. When an anti-roll moment is provided by the gyro stabilizer, the roll angle returns to the original state in a short time, and the roll rate gradually returns to the original state after the sudden change in the rolling moment, as shown in red solid lines.

Figure 10(c) and (d) shows that TTR and SSMA dropped to 0 at $4 \mathrm{~s}$. At this time, the vehicle reached a critical unstable state, while SSMA continued its decrease to a negative value, and the vehicle rolled over. After the roll moment control is carried out, SSMA is gradually returned from $0^{\circ}$ to $36^{\circ}$ and remained unchanged. TTR returned to the normal value within $2 \mathrm{~s}$, and the vehicle turned from the unstable state to the steady state. Therefore, the anti-rollover robust control can effectively prevent the vehicle from rolling over based on roll moment control and TTR rollover warning.

\section{Test verification}

To further verify the effectiveness of the proposed rollover control scheme, we have adopted a home-built articulated wheel loader vehicle to conduct real rollover control tests, which is shown in Figure 11. This vehicle is scaled down version of a real articulated wheeled loader vehicle with a ratio of 1:5. It has kept all the key mechanical features: articulated steering, swinging rear drive axle, boom and no suspension connection. More details can be found in our previous paper. ${ }^{21}$ The vehicle has multiple sensors (acceleration sensors, gyroscopes and magnetic strength sensors) to collect vehicle status information in real time and multiple actuators (electric push rod, differential driving system, direct current (DC) motors, gyro stabilizer). In the experiment, the length, width and height of the gyro stabilizer 


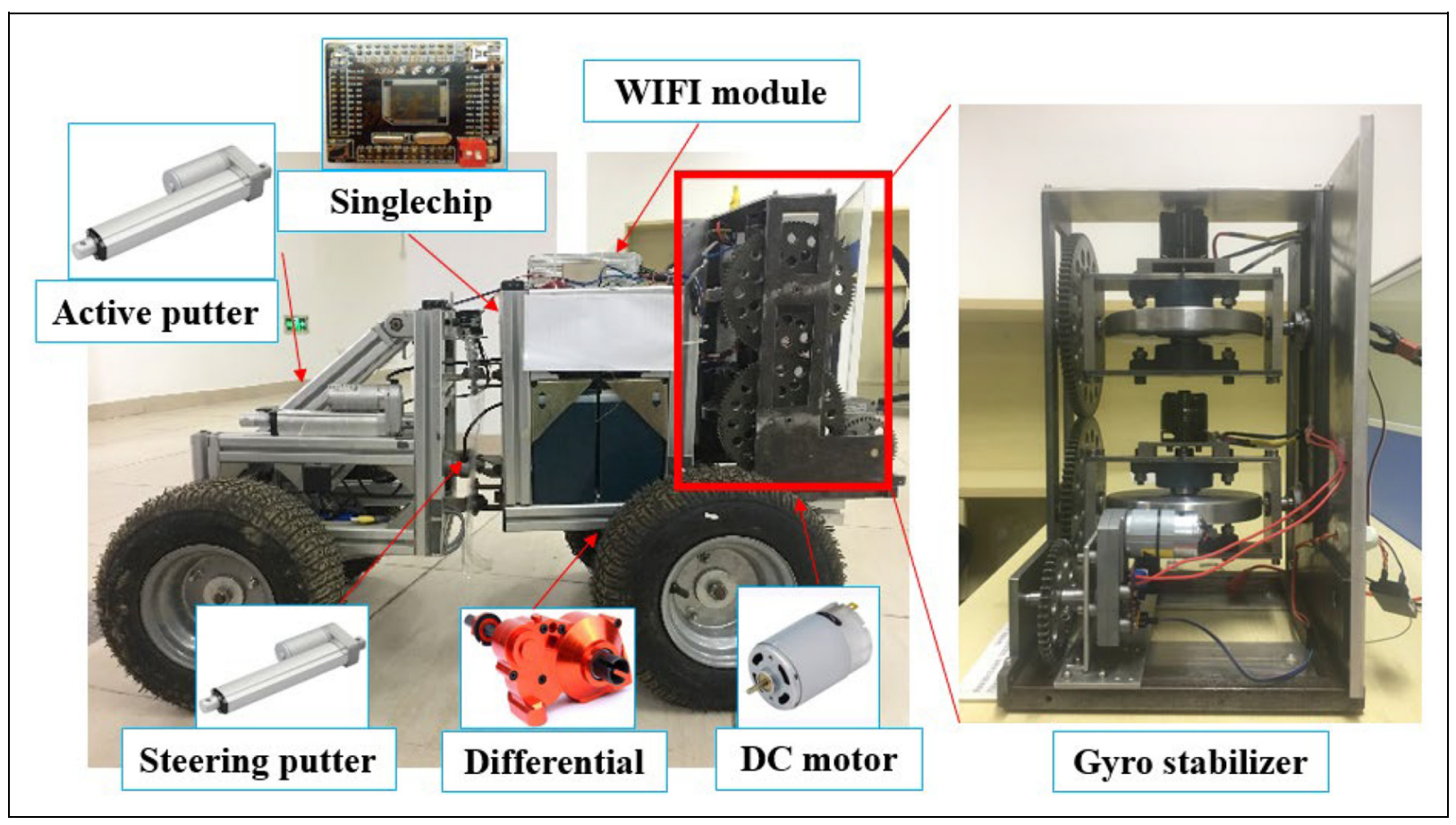

Figure I I. A home-built articulated wheel loader vehicle.

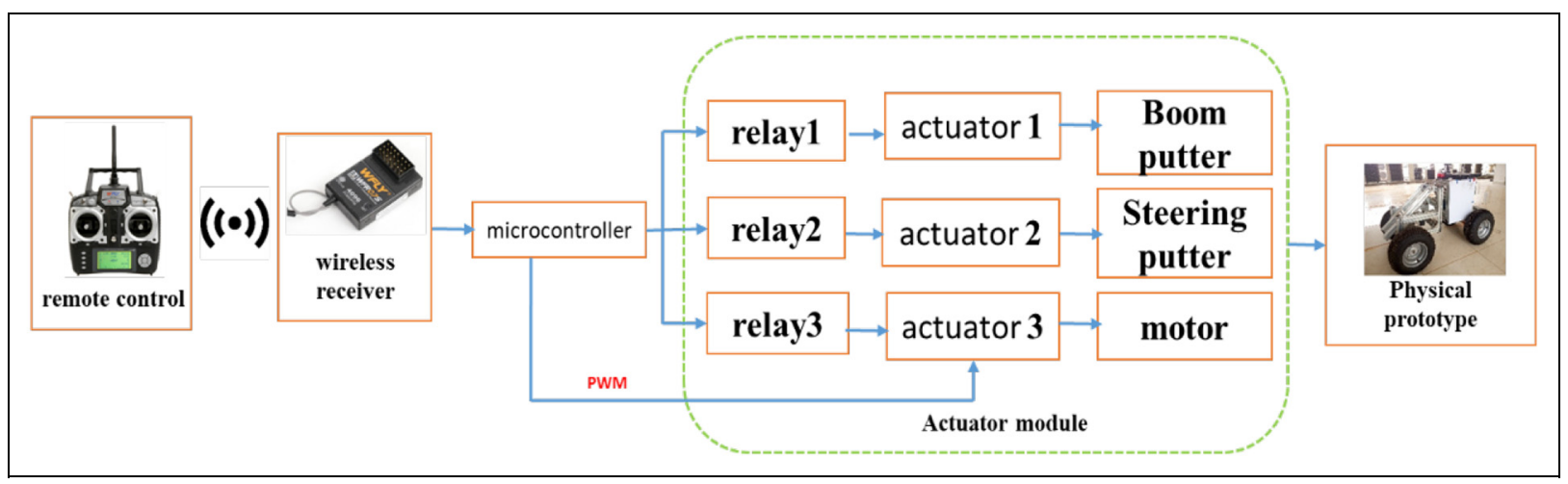

Figure 12. Overall control principle of the prototype vehicle.

are 161,161 and $416 \mathrm{~mm}$ respectively, with a weight of $23.5 \mathrm{~kg}$.

The remote controller sends a control command to the receiver module based on the direct-sequence spread spectrum (DSSS) technology. After the single chip decodes the control command, the system sends a command to the relay and the driver to control the boom lifting, steering, and forward and backward motions respectively. The vehicle speed is adjusted by changing the duty ratio of pulse-width modulation (PWM). The change of input angular velocity of its steering gear enables the gyro mechanism to provide a balanced roll moment and adjust the posture of the vehicle to prevent the vehicle from rolling over.

As the actual running speed of the articulated wheeled loader vehicle is about $7-40 \mathrm{~km} / \mathrm{h}$, we set the running speed of our test vehicle at $0.5-2 \mathrm{~m} / \mathrm{s}$ (Figure 12). Since the articulated wheel loader operates on the non-structural road surface, we choose an arc-shaped road surface obstacle according to the physical test vehicle. Based on body size and tire size, we chose an arc-shaped obstacle with a chord length of $0.16 \mathrm{~m}$ and a string height of $0.08 \mathrm{~m}$. Straight line obstacle detection experiment is conducted at a speed of $1.5 \mathrm{~m} / \mathrm{s}$.

Figure 13 shows the anti-rollover control effect on our test vehicle. More specifically, Figure 13(a) and (b) shows that the vehicle roll angle and roll rate continuously increase until the vehicle rollover (dashed blue lines) due to an increased vehicle speed, where the gyro stabilizer roll moment control is not applied. After the application of the gyro stabilizer roll torque control, the roll angle returns to the original state in a short time and the roll rate gradually returns to the original state after the sudden change in the rolling moment.

Figure 13(c) and (d) shows that TTR and SSMA dropped to 0 at around $2 \mathrm{~s}$. When active rollover 


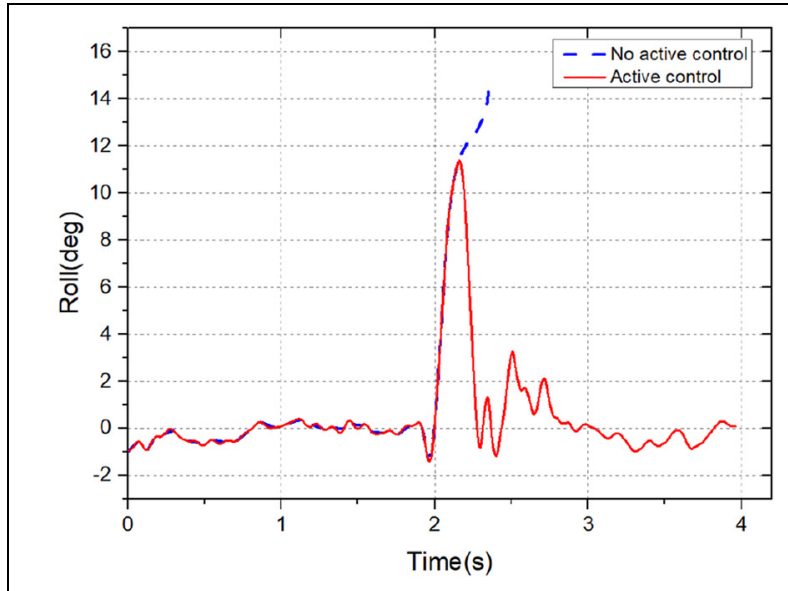

(a)

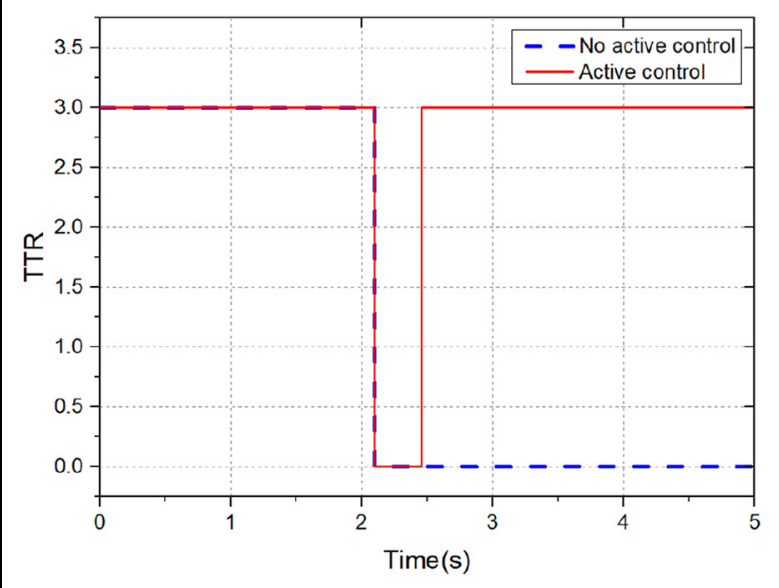

(c)

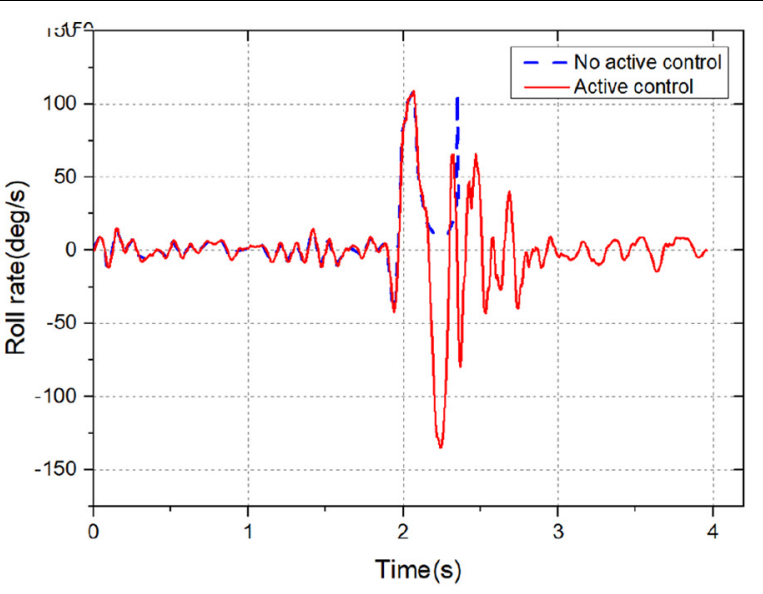

(b)

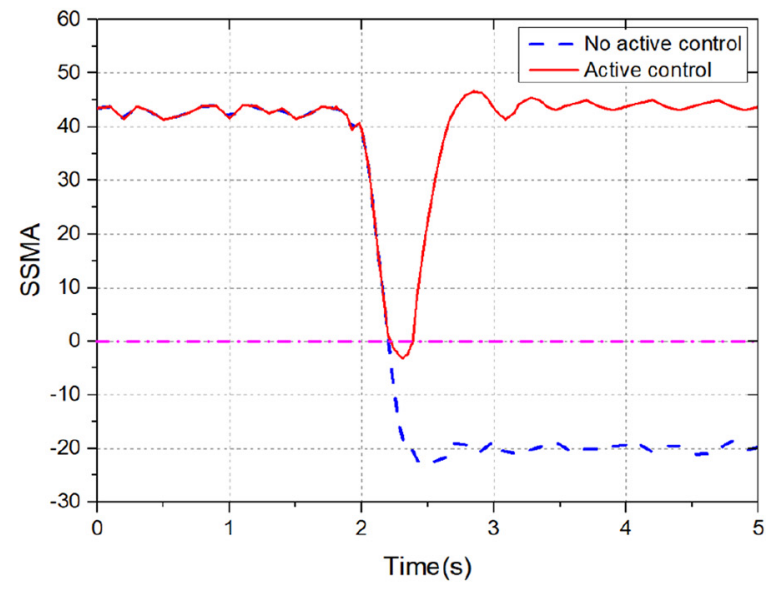

(d)

Figure 13. Anti-rollover control effects on our test vehicles at $1.5 \mathrm{~m} / \mathrm{s}$ : (a) roll angle, (b) roll rate, (c) TTR and (d) SSMA.

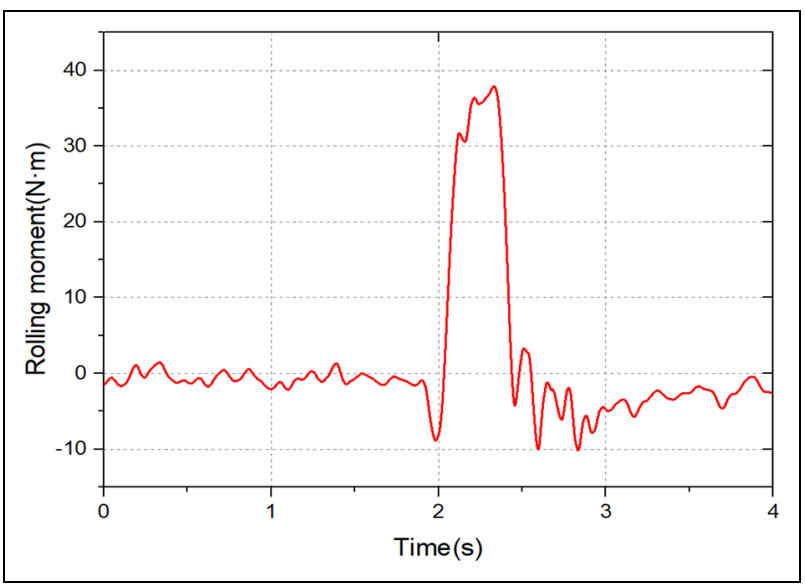

Figure 14. The roll moment applied by the anti-rollover control.

control was not applied, SSMA continuously decreased to a negative value and TTR stayed at 0 . In this case, the vehicle was rolled over. When active rollover control was applied, SSMA was gradually returned from $0^{\circ}$ to $45^{\circ}$ and TTR rapidly returned to the normal set value. The test vehicle was turned from the unstable state to the steady state. Therefore, the anti-rollover robust control can effectively prevent the vehicle from rolling over based on roll moment control and TTR rollover warning. Figure 14 shows the roll moment applied by the anti-rollover control. The roll moment control can provide a maximum anti-roll moment of $38 \mathrm{Nm}$ when the gyro stabilizer is turned on.

\section{Conclusion}

In this article, single-frame control moment gyros were deployed on an articulated wheeled loader vehicle as a stabilizer, which can actively adjust the attitude of the vehicle and prevent the vehicle from rolling over. A detailed simulation at different vehicle speeds was conducted to verify effectiveness of the proposed approach. Simulation analysis made it clear that the critical speed of the articulated wheeled loader vehicle under steadystate circumferential conditions is obtained by the proposed approach. 
Furthermore, a home-built articulated wheel loader vehicle with gyro stabilizer was deployed in real experiments under straight-through obstacle conditions. The vehicle speed was set at $1.5 \mathrm{~m} / \mathrm{s}$ according to the similarity theory. The results showed that the roll angle of the vehicle was significantly reduced after the application of the gyro stabilizer on roll torque control. The SSMA and TTR can quickly returned to the normal value. The vehicle is able to return to the stable driving state from the potential vehicle rollover. Moreover, the proposed gyro stabilizer reduces the mass of the rear body by replacing the original counterweight.

However, the high-speed operation of the gyro stabilizer consumes the additional energy. Therefore, our next stage of research will focus on how to make a compromise between speed and energy consumption so that the gyro stabilizer can achieve high efficiency.

\section{Declaration of conflicting interests}

The author(s) declared no potential conflicts of interest with respect to the research, authorship, and/or publication of this article.

\section{Funding}

The author(s) disclosed receipt of the following financial support for the research, authorship, and/or publication of this article: This work was supported by the National Natural Science Foundation of China (grant nos 51575463 and 51975495) and the Key Project in Science and Technology Plan of Xiamen (grant no. 3502Z20191019).

\section{ORCID iD}

Qingyuan Zhu (iD https://orcid.org/0000-0001-55215023

\section{References}

1. Els PS, Theron NJ, Uys PE, et al. The ride comfort vs. handling compromise for off-road vehicles. $J$ Terramechanics 2007; 44: 303-317.

2. Viano DC and Parenteau CS. Rollover crash sensing and safety overview. SAE technical paper 0148-7191, 2004.

3. Drakunov S, Ozguner U, Dix P, et al. ABS control using optimum search via sliding modes. IEEE T Contr Syst T 1995; 3: 79-85.

4. Chu L, Gu J, Liu M, et al. Study on CAN communication of EBS and braking performance test for commercial vehicle. In: IEEE vehicle power and propulsion conference, Arlington, TX, 9-12 September 2007, pp.849-852. New York: IEEE.
5. Wang $\mathrm{F}$ and Chen $\mathrm{Y}$. Dynamics and control of a novel active yaw stabilizer to enhance vehicle lateral motion stability. J Dyn Syst: T ASME 2018; 140: 081007.

6. Wang $\mathrm{F}$ and Chen $\mathrm{Y}$. A novel active rollover prevention for ground vehicles based on continuous roll motion detection. J Dyn Syst: T ASME 2019; 141: 011010.

7. Goodarzi A, Naghibian M, Choodan D, et al. Vehicle dynamics control by using a three-dimensional stabilizer pendulum system. Vehicle Syst Dyn 2016; 54: 1671-1687.

8. Goodarzi A, Diba F and Esmailzadeh E. Innovative active vehicle safety using integrated stabilizer pendulum and direct yaw moment control. J Dyn Syst: T ASME 2014; 136: 051026.

9. Sorniotti A, Morgando A and Velardocchia M. Active roll control: system design and hardware-in-the-loop test bench. Vehicle Syst Dyn 2006; 44: 489-505.

10. Bishop RH, Paynter SJ and Sunkel JW. Adaptive control of space station with control moment gyros. IEEE Contr Syst Mag 1992; 12: 23-28.

11. Thornton B, Ura T, Nose Y, et al. Zero-G class underwater robots: unrestricted attitude control using control moment gyros. IEEE J Oceanic Eng 2007; 32: 565-583.

12. Park $\mathbf{J}$ and Jung S. Development and control of a singlewheel robot: practical mechatronics approach. Mechatronics 2013; 23: 594-606.

13. $\mathrm{Xu} \mathrm{Y}$ and $\mathrm{Au} \mathrm{S}-\mathrm{W}$. Stabilization and path following of a single wheel robot. IEEE-ASME T Mech 2004; 9: 407-419.

14. Zhu Y, Gao Y, Xu C, et al. Adaptive control of a gyroscopically stabilized pendulum and its application to a single-wheel pendulum robot. IEEE-ASME T Mech 2015; 20: 2095-2106.

15. Spry SC and Girard AR. Gyroscopic stabilisation of unstable vehicles: configurations, dynamics, and control. Vehicle Syst Dyn 2008; 46: 247-260.

16. Mashadi B, Mokhtari-Alehashem $\mathrm{M}$ and Mostaghimi $\mathrm{H}$. Active vehicle rollover control using a gyroscopic device. Proc IMechE, Part D: J Automobile Engineering 2016; 230: 1958-1971.

17. Mashadi B and Gowdini M. Vehicle dynamics control by using an active gyroscopic device. J Dyn Syst: T ASME 2015; 137: 121007

18. Chen B-C and Peng H. Differential-braking-based rollover prevention for sport utility vehicles with human-inthe-loop evaluations. Vehicle Syst Dyn 2001; 36: 359-389.

19. Zhu Q, Yi J, Chen H, et al. Lateral stability simulation and analysis for wheel loaders based on the steady-state margin angle. Int J Model Ident Contr 2014; 22: 185-194.

20. Deimel RF. Mechanics of the gyroscope. Nature 1931; 128: 289.

21. Zhu Q, Xiao C, Hu H, et al. Multi-sensor based online attitude estimation and stability measurement of articulated heavy vehicles. Sensors 2018; 18: 212.

22. Wu XF, Yang $\mathrm{CP}$, Zhu Q, et al. Building a novel dynamics rollover model for critical instability state analysis of articulated multibody vehicles. Int J Heavy Veh Syst 2019; 1(1): 1 . 